\title{
molecules
}

ISSN 1420-3049

www.mdpi.com/journal/molecules

Article

\section{Essential Oil from Berries of Lebanese Juniperus excelsa M. Bieb Displays Similar Antibacterial Activity to Chlorhexidine but Higher Cytocompatibility with Human Oral Primary Cells}

\section{Barbara Azzimonti ${ }^{1,2}$, Andrea Cochis ${ }^{2,3}$, Marc El Beyrouthy ${ }^{4}$, Marcello Iriti ${ }^{5, *}$, Francesca Uberti ${ }^{2,6}$, Rita Sorrentino ${ }^{1}$, Manuela Miriam Landini ${ }^{1}$, Lia Rimondini ${ }^{2,3}$ and Elena Maria Varoni ${ }^{7, *}$}

1 Laboratory of Applied Microbiology, Department of Health Sciences, University of Piemonte Orientale, via Solaroli 17, Novara 28100, Italy; E-Mails: barbara.azzimonti@med.uniupo.it (B.A.); ritasorr@libero.it (R.S.); manuela.landini@med.uniupo.it (M.M.L.)

2 Consorzio Interuniversitario per la Scienza e Tecnologia dei Materiali (INSTM), via Giusti 9, Florence 50121, Italy; E-Mails: andrea.cochis@med.uniupo.it (A.C.); francesca.uberti@med.uniupo.it (F.U.); lia.rimondini@med.uniupo.it (L.R.)

3 Laboratory of Biomedical and Dental Materials, Department of Health Sciences, University of Piemonte Orientale, via Solaroli 17, Novara 28100, Italy

4 Department of Agricultural Sciences, Holy Spirit University of Kaslik, Kaslik B. P. 446, Jounieh, Lebanon; E-Mail: marc.beyrouthy@gmail.com

5 Department of Agricultural and Environmental Sciences, Milan State University, via Celoria, Milan 20133, Italy

6 Laboratory of Cellular Physiology, Department of Translational Medicine, University of Piemonte Orientale, via Solaroli 17, Novara 28100, Italy

7 Department of Biomedical, Surgical and Dental Sciences, Milan State University, via Beldiletto 1, Milan 20142, Italy

* Authors to whom correspondence should be addressed; E-Mails: marcello.iriti@unimi.it (M.I.); elena.varoni@unimi.it (E.M.V.); Tel.: +39-02-503-16766 (M.I.); +39-02-503-19017 (E.M.V); Fax: +39-02-503-16781 (M.I.).

Academic Editor: Derek J. McPhee

Received: 28 April 2015 / Accepted: 12 May 2015 / Published: 21 May 2015

\footnotetext{
Abstract: Chlorhexidine (CHX), one of the most effective drugs administered for periodontal treatment, presents collateral effects including toxicity when used for prolonged periods;
} 
here, we have evaluated the bactericidal potency and the cytocompatibility of Juniperus excelsa M. Bieb essential oil (EO) in comparison with $0.05 \% \mathrm{CHX}$. The EO was extracted from berries by hydrodistillation and components identified by gas chromatography and mass spectrometry. Bacterial inhibition halo analysis, quantitative cell viability 2,3-bis(2methoxy-4-nitro-5-sulphophenyl)-5-[(phenyl amino) carbonyl]-2 $H$-tetrazolium hydroxide assay (XTT), and colony forming unit (CFU) count were evaluated against the two biofilm formers Aggregatibacter actinomycetemcomitans and Streptococcus mutans. Finally, cytocompatibility was assessed with human primary gingival fibroblasts (HGF) and mucosal keratinocytes (HK). The resulting EO was mainly composed of monoterpene hydrocarbons and oxygenated monoterpenes. An inhibition halo test demonstrated that both bacteria were sensitive to the EO; XTT analysis and CFU counts confirmed that 10 -fold-diluted EO determined a statistically significant $(p<0.05)$ reduction in bacteria count and viability towards both biofilm and planktonic forms in a comparable manner to those obtained with $\mathrm{CHX}$. Moreover, EO displayed higher cytocompatibility than $\mathrm{CHX}$ $(p<0.05)$. In conclusion, EO exhibited bactericidal activity similar to CHX, but a superior cytocompatibility, making it a promising antiseptic alternative to $\mathrm{CHX}$.

Keywords: oral health; dental caries; periodontitis; antibiotic resistance; $\alpha$-pinene; Streptococcus mutans; Aggregatibacter actinomycetemcomitans

\section{Introduction}

A number of biological niches are integrated into the human body, each of which is colonized by commensal organisms that, numerically speaking, overwhelm the eukaryotic cells, and that protect the organism from infection by pathogenic species. Their complexity has been characterized using new tools in metagenomics, developed within the Microbiome Project [1].

The oral cavity is one of the most important biological niches, containing hundreds of different species of bacteria, viruses, protozoa, and mycetes; these can become pathogens in response to drastic changes in their microenvironment, which occur normally throughout human life, and are normal in microbial physiology [2].

Supragingival plaque is mainly composed of Gram-positive bacteria, comprising Streptococcus sanguinis, S. mutans, S. mitis, S. salivarius, and lactobacilli, whereas the subgingival plaque primarily includes Gram-negative anaerobic bacteria, such as Aggregatibacter actinomycetemcomitans, Tannerella forsythia, Campylobacter spp., Capnocytophaga spp., Eikenella corrodens, Fusobacterium nucleatum, Porphyromonas gingivalis, Prevotella intermedia, and oral spirochetes such as Treponema denticola. In both the supragingival and the subgingival areas, the microbial communities on teeth and gingival tissues can accumulate high concentrations of bacterial metabolites in their microenvironment (e.g., fatty acid end-products, ammonia, hydrogen peroxide, oxidants and carbon dioxide), further influencing the growth of other bacterial species.

Dental caries is closely related to the presence on the tooth surface of the oral biofilm, i.e., dental plaque, containing, among others, bacteria such as $S$. mutans, able to adhere to the tooth, proliferate, 
and produce lactic acid, which dissolves the mineralized components of dental enamel and dentine. In the presence of sugars, S. mutans overwhelms the non-acid producers Streptococcus spp., which compose the supragingival biofilm.

Caries is a very widespread disease, particularly in groups and populations living in poor socio-economic conditions. It severely affects the patient's quality of life, because of acute pain as well as the progressive loss of dental hard tissue, and compromises related functions (mastication and aesthetics) leading, in the most severe cases, to tooth extraction [3].

Another possible result of oral microflora imbalance is the oral-biofilm-related disease periodontitis, a chronic inflammatory disease of the periodontium, i.e., the apparatus supporting the tooth in the alveolus; this condition affects nearly 65 million adults in the United States [4]. It is associated with the overgrowth of several pathogens that thus dominate the other bacteria. These include the micro-aerophylic bacteria of the biofilm, particularly A. actinomycetemcomitans; this latter species is a member of the natural resident microflora related to highly aggressive periodontitis. As indicated by the World Health Organization, periodontitis is a global issue, since it may be associated to certain autoimmune disorders and systemic inflammatory processes, e.g., coronary heart disease, metabolic imbalance, and complications in pregnancy [5]. For these reasons, countless diagnostic and therapeutic attempts have been made targeting the condition, and new strategies or electrochemically induced anatase activity have been attempted to eradicate this poly-microbial disease [6,7].

Concerns over antibiotic resistance are increasingly pressing, and it is important to restore the natural local microflora balance [8]. These strategies, combined or otherwise with the use of antimicrobial agents, seek to reduce or eliminate the extensive inflammatory response, while promoting proper local immune responses, hopefully with little or no host toxicity. The most widely employed and effective antimicrobial agent, with almost 40 years of use in a number of clinical applications, mainly in dentistry but also in dermatology, urology, gynecology and the veterinary field, is the FDA (Food and Drug Administration)-approved chlorhexidine (CHX) [9]. This bis-biguanide base, with cationic structure at physiological $\mathrm{pH}$, has demonstrated wide-spectrum antibacterial activity. In dentistry, it is the most frequently prescribed and effective compound for plaque control, as an adjunct to mechanical oral hygiene [10], and has acquired the role of "gold standard" oral antiseptic agent, mainly in mouthwash formulations. However, despite CHX's well-known properties, undesirable side effects can occur [11] and this molecule has been reported to be cytotoxic [12]. In the case of CHX abuse, this can lead to ulcerative and desquamative oral lesions [9]. Interestingly, in the perspective of long-term clinical use, low concentrations of CHX $(0.05 \%-0.06 \%)$ have been reported to retain adequate anti-plaque efficacy, while reducing adverse effects [13].

Scientific interest is now growing with regard to new active ingredients other than $\mathrm{CHX}$ able to control the proliferation of pathogens, but preserving those microorganisms beneficial for the microenvironment, in full respect of host tissue integrity [14]. Certain essential oils (EOs), in particularly those extracted from Lippia sidoides by hydrodistillation of fresh leaves, are successful alternative antiseptic agents for oral care [10,15]. A recent meta-analysis reported a reduction similar or even superior to that produced by CHX in both dental plaque and gingival inflammation indexes when EOs were used for six months [10]. Interestingly, commercially available EOs, although not entirely innocuous, show milder side effects than CHX [16]. 
Based on these premises, research efforts are now focusing on isolating novel plant-derived EOs, able to provide antibacterial effects against oral pathogens without affecting the oral microenvironment, that possess high biocompatibility.

Juniperus excelsa is a tree species belonging to the Cupressaceae family, which includes about 70 species widespread in Lebanon; it is used in traditional herbal medicine for its antifungal, disinfectant, and insect-repellent properties. Recent studies have evidenced its antimicrobial activity against the Gram positive $S$. aureus and the dermatophyte Trichophyton rubrum $[17,18]$. The present study aimed to better define the antibacterial properties of the EO extracted from the berries of $J$. excelsa, comparing them to those of digluconate $\mathrm{CHX}$, against the two oral pathogens $S$. mutans and against $A$. actinomycetemcomitans. Inhibition halo, cell viability and colony-forming unit count were evaluated. The cytocompatibility of the EO versus primary human gingival fibroblasts and epithelial keratinocytes was also verified, to confirm the compounds' in vitro safety.

\section{Results and Discussion}

\subsection{Essential Oil Characterization}

The yield of the EO extracted from the berries of $J$. excelsa was $1.17 \%$. The chemical composition of the EO is detailed in Table 1. Twenty-seven constituents were detected, in variable amounts. The components identified and quantified accounted for $98.1 \%$ of the total EO, mainly composed of monoterpene hydrocarbons. In particular, $\alpha$-pinene was the most abundant compound $(86.8 \%)$, while myrcene were the second most abundant metabolite (3.2\%).

Table 1. Chemical composition (\%) and yield of essential oil obtained by hydrodistillation from berries of Juniperus excelsa M. Bieb.

\begin{tabular}{|c|c|c|c|c|}
\hline \multirow{2}{*}{$\mathbf{R}_{\mathbf{i}}{ }^{\mathbf{a}}$} & \multirow{2}{*}{$\mathbf{R}_{\mathbf{i}}{ }^{\mathbf{b}}$} & Yield \% (v/w) & \multirow{2}{*}{ Identification $^{c}$} & \multirow{2}{*}{1.17} \\
\hline & & Compound ID & & \\
\hline 938 & 1076 & $\alpha$-Pinene & $\mathrm{R}_{\mathrm{i}}, \mathrm{MS}^{\mathrm{d}}, \mathrm{CoGC}^{\mathrm{e}}$ & $86.8^{f}$ \\
\hline 980 & 1118 & $\beta$-Pinene & $\mathrm{R}_{\mathrm{i}}, \mathrm{MS}, \mathrm{CoGC}$ & 2.5 \\
\hline 993 & 1174 & Myrcene & $\mathrm{R}_{\mathrm{i}}, \mathrm{MS}, \mathrm{CoGC}$ & 3.2 \\
\hline 1013 & 1159 & $\delta$-3-Carene & $\mathrm{R}_{\mathrm{i}}, \mathrm{MS}$ & 2.4 \\
\hline 1030 & 1203 & Limonene & $\mathrm{R}_{\mathrm{i}}, \mathrm{MS}$, CoGC & 2.2 \\
\hline 1057 & 1255 & $\gamma$-Terpinene & $\mathrm{R}_{\mathrm{i}}, \mathrm{MS}$, CoGC & 0.3 \\
\hline 1143 & 1532 & Camphor & $\mathrm{R}_{\mathrm{i}}, \mathrm{MS}, \mathrm{CoGC}$ & $\mathrm{T}$ \\
\hline 1152 & 1683 & trans-Verbenol & $\mathrm{R}_{\mathrm{i}}, \mathrm{MS}$ & $\mathrm{T}$ \\
\hline 1165 & 1587 & Pinocarvone & $\mathrm{R}_{\mathrm{i}}, \mathrm{MS}$ & $\mathrm{T}$ \\
\hline 1182 & 1864 & $p$-Cymen-8-ol & $\mathrm{R}_{\mathrm{i}}, \mathrm{MS}$ & $\mathrm{T}$ \\
\hline 1189 & 1706 & $\alpha$-Terpineol & $\mathrm{R}_{\mathrm{i}}, \mathrm{MS}$ & 0.4 \\
\hline 1217 & 1725 & Verbenone & $\mathrm{R}_{\mathrm{i}}, \mathrm{MS}$ & 0.1 \\
\hline 1284 & 1597 & Bornyl acetate & $\mathrm{R}_{\mathrm{i}}, \mathrm{MS}$, CoGC & $\mathrm{T}$ \\
\hline 1477 & 1726 & D-Germacrene & $\mathrm{R}_{\mathrm{i}}, \mathrm{MS}$ & $\mathrm{T}$ \\
\hline 1515 & 1776 & $\delta$-Cadinene & $\mathrm{R}_{\mathrm{i}}, \mathrm{MS}$ & $\mathrm{T}$ \\
\hline \multirow[t]{3}{*}{1604} & 2160 & Cedrol & $\mathrm{R}_{\mathrm{i}}, \mathrm{MS}, \mathrm{CoGC}$ & $\mathrm{T}$ \\
\hline & & Monoterpene hydrocarbons & & 97.3 \\
\hline & & Oxygenated monoterpenes & & 0.8 \\
\hline
\end{tabular}

${ }^{\mathrm{a}}$ : Retention index determined on a HP-5MS column; ${ }^{\text {b}}$ : retention index determined on an Innovax column;

c: $\mathrm{R}_{\mathrm{i}}$ retention index identical to reported value; ${ }^{\mathrm{d}}$ : MS: identification by comparison of mass spectra;

e: Co-GC: retention time identical to that of authentic compounds; ${ }^{\mathrm{f}}$ : bold numbers indicate percentages above $2 \%$, showing major components; $\mathrm{T}=$ traces, less than $0.05 \%$. 


\subsection{Antibacterial Activity}

Both bacterial strains were found to be sensitive to the tested EO from $J$. excelsa berries. In particular, pure EO produced larger inhibition halos than $0.05 \% \mathrm{CHX}$, both on $S$. mutans (Figure 1A) and on A. actimomycetemcomitans (Figure 2A), with a statistically-significant difference in comparison with controls $(p<0.05)$. Inhibition halo areas of $1 / 10$ diluted EO were smaller than CHX, though still significant towards controls for both $S$. mutans (Figure 1B) and A. actimomycetemcomitans (Figure 2B).
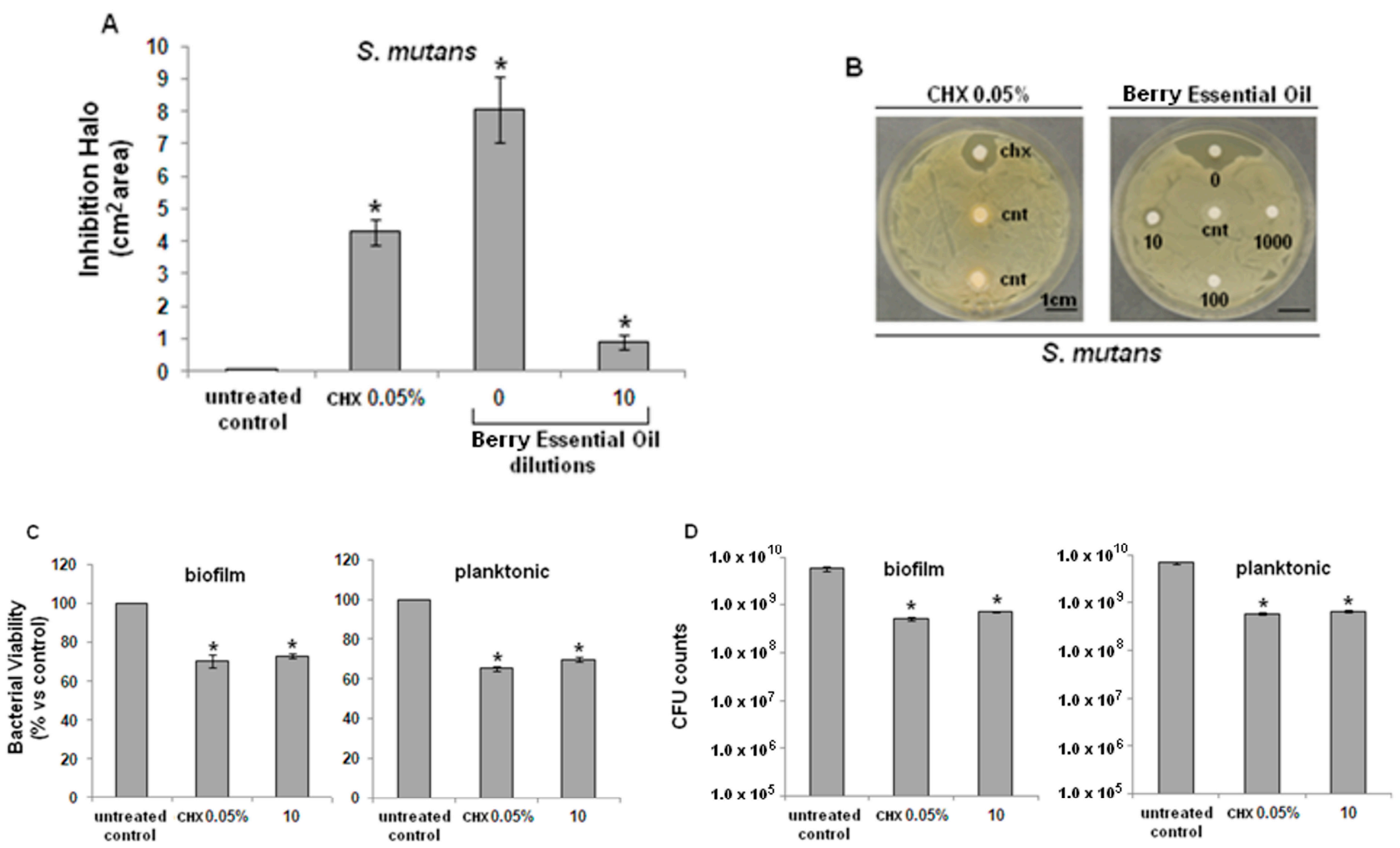

Figure 1. Antibacterial activity of $J$. excelsa EO against $S$. mutans. (A) Bacteria growth was inhibited by pure (0) or 1/10 diluted EO (10); inhibition was statistically significant in comparison with controls (cnt) $(p<0.05$, indicated by the $*)$; (B) higher EO dilutions (100 or 1000) were ineffective; (C) XTT assay revealed a similar activity between CHX and EO (10), statistically different from controls $(* p<0.05)$ for both biofilm (left) and planktonic (right) cells; (D) CFUs counts showed that CHX and EO (10) determined a similar significant reduction of about $1.5 \mathrm{logs}$ in comparison with control $(* p<0.05)$ for both biofilm (left) or planktonic (right) cells. Data are expressed as mean \pm standard deviation.

Results from the metabolic bacterial assay (XTT) showed that EO significantly decreased the viability of $S$. mutans (Figure 1C) and A. actimomycetemcomitans (Figure 2C), both in their biofilm (left graphic) and planktonic (right graphic) forms, compared with untreated controls $(p<0.05)$, similarly to CHX. Lastly, CFU counts of S. mutans (Figure 1D) and A. actimomycetemcomitans (Figure 2D), both in their biofilm (left graphic) and planktonic forms (right graphic) confirmed the data obtained with the XTT test. 


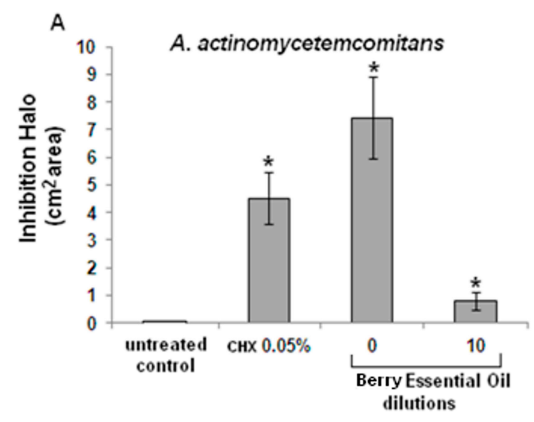

B
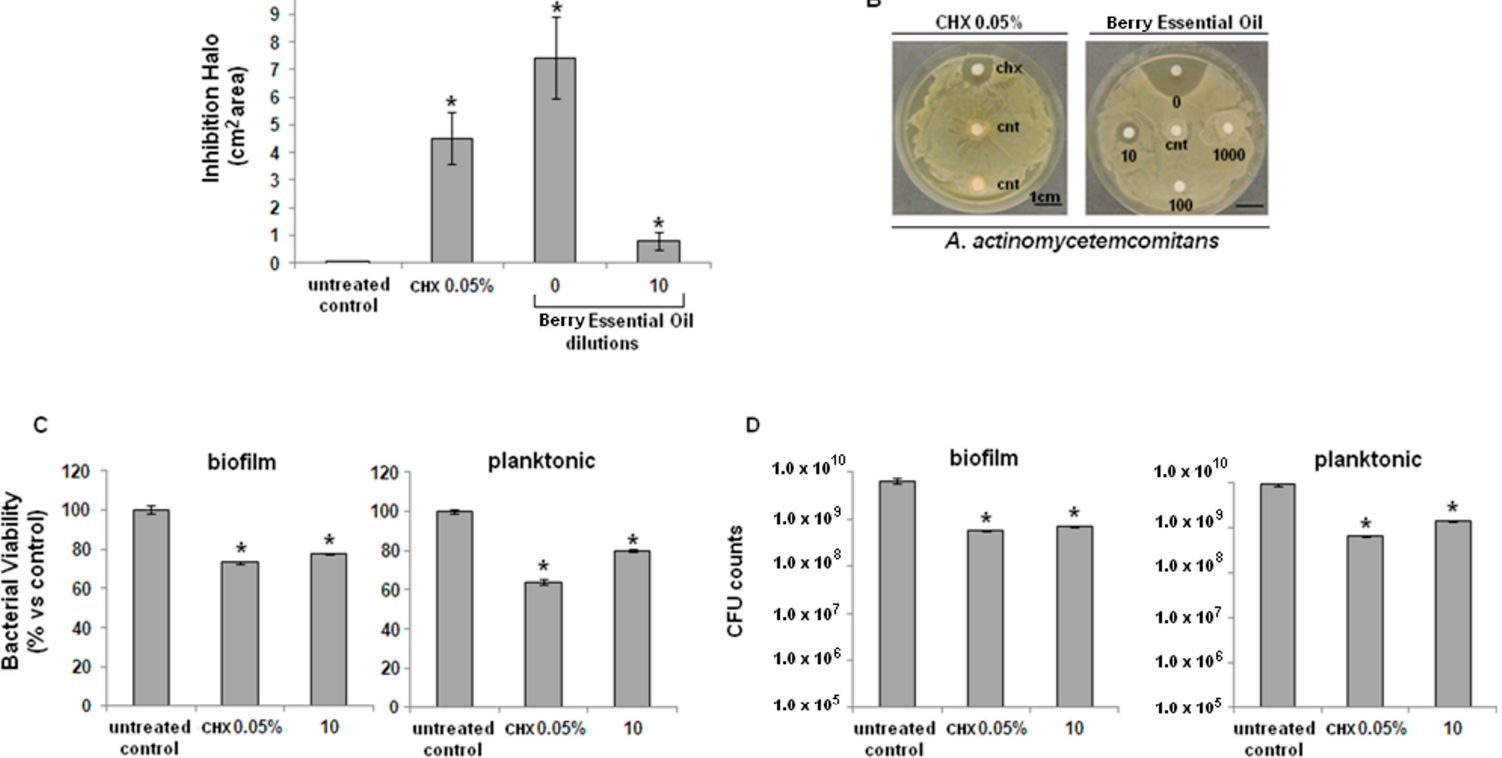

Figure 2. Antibacterial activity of $J$. excelsa EO against A. actinomycetemcomitans. (A) Bacteria growth was inhibited by pure (0) or 1/10 diluted EO (10); inhibition was statistically significant in comparison with controls (cnt) $(p<0.05$, indicated by the *); (B) higher EO dilutions (100 or 1000) were ineffective; (C) XTT assay revealed a similar activity between CHX and EO (10), statistically different towards controls (* $p<0.05)$ for both biofilm (left) and planktonic (right) cells; (D) CFUs counts showed that CHX and EO (10) determined a similar significant reduction of about $1.5 \mathrm{logs}$ in comparison with control (* $p<0.05)$ for both biofilm (left) or planktonic (right) cells. Data are expressed as mean \pm standard deviation.

\subsection{Cytocompatibility}

The effective 1/10 EO dilution determined a toxicity towards human cells that was significant to both gingival fibroblasts (HGFs, Figure 3A) and mucosal keratinocytes (HKs, Figure 3B); similar results were obtained with $\mathrm{CHX}$. However, when comparing the 1/10 diluted EO and CHX groups, a statistical differences was noticed for both cell types, revealing a higher toxicity for $\mathrm{CHX}$ in comparison with $\mathrm{EO}(p<0.05)$.

\subsection{Discussion}

$J$. excelsa EOs are novel active ingredients now being investigated for their potential as antiseptic agents for biomedical applications. They have been recently assayed for antimicrobial activity against the Gram-positive $S$. aureus and the dermatophyte Trichophyton rubrum [17,18]. This study, for the first time, investigated the preclinical efficacy of these products in oral care. EO from $J$. excelsa berries was tested against two major oral pathogens, i.e., A. actinomycetemcomitans and S. mutans, and, of note, primary human cells were used as the most appropriate way to test cytocompatibility. 

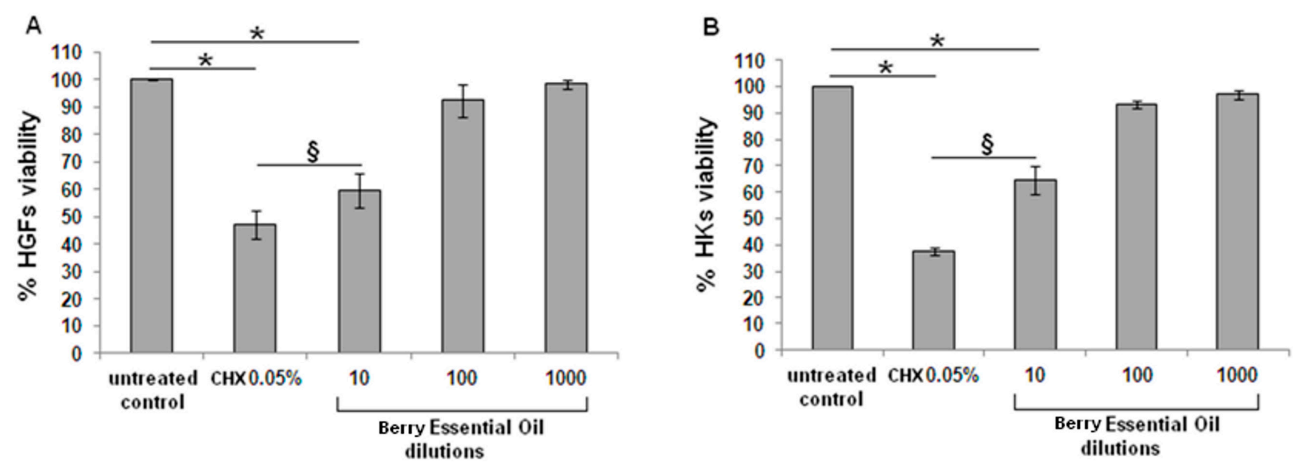

Figure 3. In vitro cytocompatibility assay. The MTT test revealed that EO (10) and chlorhexidine caused a significant reduction $(p<0.05$, indicated by the *) of cell viability for both fibroblasts (HGFs, left) and keratinocytes (HKs, right) in comparison with untreated control cells. However, EO (10) resulted significantly less toxic than CHX for both cell types $(p<0.05$, indicated by the $\S)$. Higher oil dilutions (100 and 1000) were not toxic in comparison with control. Data are expressed as means \pm standard deviations.

The composition of the Lebanese $J$. excelsa EO used in this study is comparable to that of EOs from different geographical origins, previously reported in the literature, the most abundant constituent being $\alpha$-pinene [19,20], as expected for a gymnosperm. Conversely, EOs of $J$. excelsa trees, cultivated in the United States and containing $\beta$-pinene (16.4\%), limonene (11.6\%) and bornyl acetate (10.4\%) as their main constituents [21], are very different from the Middle-Eastern EOs. Interestingly, it has been proposed that the structure of the different EO components is related to their activity versus bacteria and the host cell. For instance, the presence of phenolic compounds, in particular containing the hydroxyl group, and the presence of an ester group in the structure of bornyl acetate have been reported to greatly enhance EO activity against several microorganisms [22]. This suggests the importance of identifying specific components and moieties, as well as the relevance of testing each newly isolated EO for both antibacterial and cytotoxic effects.

In this study, the antimicrobial activity and cytocompatibility of $J$. excelsa EO were compared to those of CHX, a FDA-approved chemical antiseptic agent well known for its wide spectrum of action. Due to its ability to lyse the bacterial cell wall, by altering the osmotic balance of the bacterial cell, CHX is currently in use for numerous clinical applications, ranging from hand antisepsis in surgery to daily oral care. In particular, it can be considered the gold standard for dental plaque control, due to its efficacy against oral pathogens [9].

The present results support the antibacterial efficacy of EOs against A. actinomycetemcomitans and S. mutans. The inhibition halo test demonstrated the ability of EO to reduce the growth of bacteria. However, this assay alone cannot provide precise information concerning the relative effectiveness of one drug compared to another, since the size of the inhibition halo on the agar depends on several other factors. The first is the molecular weight of the compound, which inversely correlates with the size of the halo; this is followed by the compound's density, which is directly correlated to halo size; finally, the electric charge of the compound can also influence its binding to the $\mathrm{SO}_{4}{ }^{2-}$ group of the agar, and thus bacteria migration. For this reason, after having established the general sensitivity of the test strains to the EO, a XTT reduction test and a cell propagation assay were run. These methods have 
been approved for use, but only the XTT reduction assay is widely used, since it can accurately and rapidly determine bacteria cell viability, by reducing the key interference factors. The cell propagation assay is known for its high sensitivity, but it is time-consuming and more sensitive to cell aggregation levels than is the XTT test. Since an inhibition halo test provides only a general information on the antibacterial efficacy of the compound, it needs to be confirmed by further and more accurate evidence, via XTT and cell propagation assays. The experiments reported here show that the 1/10 diluted $J$. excelsa EO possess antimicrobial action against both $A$. actinomycetemcomitans and $S$. mutans, and that it is comparable to that of CHX used at a concentration of $0.05 \%$. These data are consistent with reported findings of equivalent, or higher, in vitro antibacterial activity for EOs compared to CHX [23-25]. Of note, J. excelsa EOs showed lower cytotoxicity against both HGFs and HKs than CHX treatment; this is consistent with a study on human periodontal ligament fibroblasts [26]. The present study focused on the cytocompatibility of EOs with HGFs and HKs; these cells represent the best in vitro cellular model, since they come from the same species and the same anatomical site where the compounds will be used in vivo (i.e., the oral cavity). Moreover, they do not show aneuploidies or alterations, which could confuse the interpretation of the cellular response and, in addition, since human primary cells were isolated from a pool of three donors, they represent the properties of an entire population.

\section{Experimental Section}

\subsection{Essential Oils}

\subsubsection{Plant Material}

In October 2011, specimens of berries were collected from a 100-year-old Juniperus excelsa M. Bieb. tree growing on a natural site on the southern slopes of Hsayya, Qartaba, Mount Lebanon $\left(34^{\circ} 05^{\prime} 55.35^{\prime \prime} \mathrm{N} 35^{\circ} 50^{\prime} 27.77^{\prime \prime} \mathrm{E}\right)$, at an altitude of about $1400 \mathrm{~m}$. The plant material was dried in the shade for four weeks. Voucher specimens were deposited with the Herbarium of Botany, Medicinal Plant and Weed Science, Faculty of Agricultural and Food Sciences of U.S.E.K., Lebanon (registry number MNI018a-n).

\subsubsection{Essentials Oil Extraction}

The EO was extracted from the berries of $J$. excelsa by hydrodistillation for $3 \mathrm{~h}$, using a Clevenger-type apparatus as indicated in the European Pharmacopoeia [27].

\subsubsection{Essential Oil Analysis}

Gas Chromatography $(G C)$. The GC analysis was carried out with a Thermo Electron apparatus (Thermo Electron Corporation, Beverly, MA, USA) equipped with a flame ionization detector (FID), an apolar DB-5 MS capillary column $(30 \mathrm{~m} \times 0.25 \mathrm{~mm}$ i.d., film thickness $0.1 \mathrm{~mm}$, Agilent Technologies, Santa Clara, CA, USA), and a polar fused-silica HP Innowax capillary column (polyethylene glycol, $50 \mathrm{~m} \times 0.20 \mathrm{~mm}$ i.d., film thickness $0.20 \mathrm{~mm}$, Agilent Technologies). The oven temperature was programmed to rise from $35^{\circ} \mathrm{C}$ to $85{ }^{\circ} \mathrm{C}$ at $5{ }^{\circ} \mathrm{C} \mathrm{min}-1$, held isothermal at $85{ }^{\circ} \mathrm{C}$ for 
$20 \mathrm{~min}$, then rising from $85^{\circ} \mathrm{C}$ to $300{ }^{\circ} \mathrm{C}$ at $10^{\circ} \mathrm{C} / \mathrm{min}$, and finally held isothermal at $300{ }^{\circ} \mathrm{C}$ for $5 \mathrm{~min}$; injector temperature, $250^{\circ} \mathrm{C}$; detector temperature, $310^{\circ} \mathrm{C}$; carrier gas, $\mathrm{He}\left(0.7 \mathrm{~mL} \mathrm{~min}^{-1}\right)$. Aliquots of $1 \mathrm{~mL}$ of the diluted samples $(1: 100 \mathrm{v} / \mathrm{v})$ were injected both manually and in splitless mode.

Gas Chromatography coupled to Mass Spectrometry (GC-MS). The GC-MS analysis was run on an Agilent 6890 gas chromatograph (Agilent Technologie) coupled with an Agilent 5975 mass-selective detector and equipped with an Agilent $7683 \mathrm{~B}$ auto sampler (injection of $1 \mathrm{~mL}$ of oil for each sample). The capillary columns and the $\mathrm{GC}$ conditions were those described above; source temperature, $310{ }^{\circ} \mathrm{C}$; transfer-line temperature, $320^{\circ} \mathrm{C}$; ionization voltage, $70 \mathrm{eV}$; mass range, 50-400 amu (full scan mode).

Identification and quantification of EO components. Identification of the $\mathrm{EO}$ constituents was based on: $(i)$ retention indices (RIs), determined relative to the $t_{\mathrm{R}}$ of $n$-alkanes $\left(\mathrm{C}_{8}-\mathrm{C}_{24}\right)$ on both capillary columns, and compared with those reported in the literature [28] or with those of authentic compounds obtained from the manufacturer (Sigma-Aldrich, Beirut, Lebanon); and (ii) mass spectra, compared with those listed in the commercial mass spectral libraries NIST, Wiley 275 and in a home-made library, or with those reported in the literature [28,29]. Standards of selected EOs of known composition (e.g., the essential oil of Rosmarinus officinalis L. from Phytosun Aroms, Plélo, France) were injected under similar conditions for the comparison of $t_{\mathrm{R}}$ and mass spectra. The relative contents of the oil components were calculated based on the GC-FID peak areas without using correction factors.

\subsection{Antibacterial Activity of Essential Oils}

\subsubsection{Bacterial Strains and Growth Conditions}

Two exponentially growing oral biofilm pathogen strains were used to evaluate the antibacterial activity of the EO: (i) Streptococcus mutans (DSMZ 20523, Leibniz Institute DSMZ-German Collection of Microorganisms and Cell Cultures, Braunschweig, Germany) and (ii) Aggregatibacter actinomycetemcomitans (DSMZ 11123). Bacteria were cultivated on blood-agar plates (Sintak S.r.l., Corsico, Milan, Italy) at $37{ }^{\circ} \mathrm{C}$, under aerobic conditions, for $48 \mathrm{~h}$ until round single colonies were obtained. Plates were then stored at $4{ }^{\circ} \mathrm{C}$ until use.

\subsubsection{Biofilm and Planktonic Bacterial Cells}

Antibacterial activity of the EO was tested against biofilm and planktonic cells of both $S$. mutans and $A$. actinomycetemcomitans species. $500 \mathrm{~mL}$ of each fresh bacterial culture were prepared by inoculating about 4-5 single colonies of each strain into Luria Bertani broth (LB, Sigma-Aldrich, Milan, Italy). Cultures were incubated at $37^{\circ} \mathrm{C}$ in a Gallenkamp orbital shaker incubator at $16 \mathrm{~g}$ for $16 \mathrm{~h}$. Exponentially-growing bacterial suspensions were then diluted in fresh LB medium at a final concentration of $1 \times 10^{8}$ cells $\mathrm{mL}^{-1}$ according to the McFarland standard 1.0. One hundred $\mu \mathrm{L}$ $\left(1 \times 10^{7}\right.$ cells $\left.\mathrm{mL}^{-1}\right)$ of the diluted cultures were collected, spotted into 96-well plates (CellStar, PBI International, Milan, Italy) and incubated at $37^{\circ} \mathrm{C}$ in rotation $(6 \mathrm{~g})$ for $90 \mathrm{~min}$ (adhesion phase). The supernatant containing planktonic cells was then removed from each well and transferred onto a new plate, while biofilm cells, attached to the bottom of the empty wells were rinsed with $100 \mu \mathrm{L}$ of fresh LB medium (separation phase). 


\subsubsection{Essential Oil Treatment}

EO and CHX were diluted in 10\% dimethyl sulphoxide (DMSO, Sigma-Aldrich) in 1x phosphate buffered saline (PBS, Sigma-Aldrich). Different dilutions of EO were added to each well containing planktonic or biofilm cells, as follows: $0=$ pure essential oil; $10=1 / 10 ; 100=1 / 100 ; 1000=1 / 1000$. Digluconate CHX at $0.05 \%$ was used as positive control, while LB medium alone plus $10 \%$ DMSO was used as untreated control. Experiments were performed in quadruplicate.

\subsubsection{Inhibition Halo}

In order to evaluate bacterial strain sensitivity towards the EO, $1 \mathrm{~mL}$ of a suspension of $1 \times 10^{7}$ bacterial cells $\mathrm{mL}^{-1}$ was spotted and distributed uniformly over the surface of Petri dishes containing LB agar medium. Plates were air dried for $20 \mathrm{~min}$ in a laminar flow hood (Heraeus, Herasafe HS 15, Burladingen, Germany) and $0.5 \mathrm{~cm}$ diameter sterile paper disks, previously soaked with $20 \mu \mathrm{L}$ of the pure/diluted EO or $0.05 \% \mathrm{CHX}$, were then placed over the plated surface. Plates were incubated for $24 \mathrm{~h}$ at $37{ }^{\circ} \mathrm{C}$ and, the following day, the inhibition halo was measured, i.e., the bacteria-free area around the treated paper disk. As untreated control, a disk soaked in LB medium alone plus $10 \%$ DMSO was placed in the centre of each plate. Experiments were performed in quadruplicate for each chemical and bacterial strain.

\subsubsection{Bacterial Cell Viability}

To assess the growth capacity of the bacterial strains after $24 \mathrm{~h}$ of direct essential oil contact compared to that of untreated controls, bacterial viability was evaluated by the validated quantitative colorimetric metabolic 2,3-bis (2-methoxy-4-nitro-5-sulphophenyl)-5-[(phenyl amino) carbonyl]-2Htetrazolium hydroxide assay (XTT, Sigma-Aldrich). Briefly, $20 \mu \mathrm{L}$ of XTT solution $\left(3 \mathrm{mg} \mathrm{mL}^{-1}\right.$ in acetone containing $0.1 \mathrm{M}$ menadione) were added to each well and plates were incubated at $37{ }^{\circ} \mathrm{C}$ for $5 \mathrm{~h}$ in the dark. $50 \mu \mathrm{L}$ were then collected from each well and centrifuged for $2 \mathrm{~min}$ at $480 \mathrm{~g}$ to remove any debris, and the optical density was evaluated using a spectrophotometer (SpectraCount, IBM, New York, NY, USA) at $690 \mathrm{~nm}$.

\subsubsection{Colonies Forming Units (CFU) Counts}

After $24 \mathrm{~h}$ of direct contact with the EO, a colony forming unit (CFU) count was conducted as described by Harrison et al. [30]. Briefly, $100 \mu \mathrm{L}$ of supernatant were collected from each well and used to perform six serial ten-fold dilutions, mixing $20 \mu \mathrm{L}$ of bacterial suspension with $180 \mu \mathrm{L}$ of sterile saline $(0.9 \% \mathrm{NaCl})$. Twenty $\mu \mathrm{L}$ were then collected from each dilution, spotted onto plates containing $\mathrm{LB}$ agar medium, and incubated for $24 \mathrm{~h}$ at $37^{\circ} \mathrm{C}$. Lastly, the CFU mL $\mathrm{mL}^{-1}$ were counted as follows:

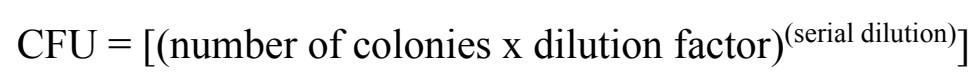

where:

number of colonies $=$ countable single round colonies;

dilution factor $=$ dilution made from the initial $1 \mathrm{~mL}$ suspension;

serial dilution $=1-6$ ten-fold dilution areas where colonies were counted. 


\subsection{Cytocompatibility Evaluation of Essential Oils}

\subsubsection{Cells}

Cytotoxic activity of EO was evaluated on pooled primary human gingival fibroblasts (HGFs) and mucosal keratinocytes (HKs). HGFs were isolated from discarded normal human gingiva, surgically resected from healthy patients. All subjects gave informed consent to participate to the study, which was conducted according to the Declaration of Helsinki. Briefly, thin sheets of mucosa were removed using a dermatome, and the epithelial layer was enzymatically detached through simple digestion with $0.5 \%$ dispase at $4{ }^{\circ} \mathrm{C} \mathrm{O} / \mathrm{N}$. The dermal layer was then minced with surgical blades and digested for $30 \mathrm{~min}$ at $37{ }^{\circ} \mathrm{C}$ with a collagenase/dispase/trypsin solution $\left(1 \mathrm{mg} \mathrm{mL}{ }^{-1}\right.$ collagenase, $0.3 \mathrm{mg} \mathrm{mL}^{-1}$ dispase, $0.25 \%$ trypsin in PBS, all from Sigma-Aldrich). Cells were then cultivated in $\alpha$-MEM (Sigma-Aldrich) supplemented with 10\% heat-inactivated fetal bovine serum FBS (Sigma-Aldrich) and $1 \%$ antibiotics-antimycotics (Anti-Anti, Sigma-Aldrich) at $37{ }^{\circ} \mathrm{C}$ in a humidified $10 \% \mathrm{CO}_{2}$ atmosphere. HK were obtained from Clonetics (Euroclone, Milan, Italy) and maintained in EpiLife ${ }^{\circledR}$ Medium (Invitrogen, Milan, Italy). Before confluence, both cell types were trypsinized, re-suspended, plated for the experiments, and used within fifteen population doublings.

\subsubsection{Cell Viability Determination}

Both HGFs and HKs $\left(2 \times 10^{4}\right.$ cells well $\left.{ }^{-1}\right)$ were seeded onto 96-well plates. Cells were allowed to adhere overnight, and then the EO was added to each well, at the same dilutions used for the antibacterial activity assay. After $24 \mathrm{~h}$ of direct contact with EOs, cell viability was determined using the colorimetric metabolic assay 3-(4,5-dimethylthiazol-2-yl)-2,5-diphenyltetrazolium bromide (MTT, Sigma-Aldrich). Briefly, $20 \mu \mathrm{L}$ of MTT solution ( $3 \mathrm{mg} \mathrm{mL}^{-1}$ in PBS) were spotted onto each well; plates were incubated for $4 \mathrm{~h}$ in the dark at $37{ }^{\circ} \mathrm{C}$ in an incubator. The medium was then removed, and the formazan crystals on the well bottom were dissolved in $100 \mu \mathrm{L}$ DMSO. Lastly, $50 \mu \mathrm{L}$ aliquots were collected from each well and the optical density measured with the spectrophotometer, at $570 \mathrm{~nm}$. Cells cultivated with medium alone plus 10\% DMSO were considered untreated controls; data were expressed as $\%$ viability related to $100 \%$ of controls. The viability of cells treated with EOs was also compared to that measured in the presence of $0.05 \% \mathrm{CHX}$. Experiments were carried out in quadruplicate.

\subsection{Statistical Analysis of Data}

Statistical analysis was performed using the Statistical Package for the Social Sciences (SPSS v. 20.0, IBM, Atlanta, GA, USA). Data were statistically compared by one-way ANOVA followed by Sheffe's test for post-hoc analysis. The significance level was set at $p<0.05$.

\section{Conclusions}

Our results support in vitro evidence of cytocompatibility and antibacterial activity of novel EO extracted from Lebanese Juniperus excelsa M. Bieb. The EO does not affect cell survival of primary HGFs and HEKs, while retaining its antibacterial activity against two common oral pathogens, 
A. actinomycetemcomitans and $S$. mutans. Conversely, the data confirm the harmful effects on cell viability of $0.05 \% \mathrm{CHX}$, whose antibacterial efficacy is comparable to that of the EOs.

Within the limitations of this preclinical study, the results suggest that innovative formulations for oral health, based on $J$. excelsa $\mathrm{EO}$, are promising candidates as safe and effective alternatives to the current gold standard antiseptic agent, i.e., CHX, which is not without cytotoxicity and adverse effects. Further investigations will be needed to confirm the clinical efficacy of these compounds, and to examine in greater depth the significance of the present findings.

\section{Acknowledgments}

We thank Frances Cooper for the English language revision.

Fondi "Ricerca Locale 2010" and "Fondazione Cariplo 2013" supported this study (University of Piemonte Orientale).

\section{Author Contributions}

M.I., B.A., A.C. and E.M.V. conceived the idea and wrote the manuscript; M.E.B. provided the essential oils and carried out GC-MS analyses; F.U., R.S. and M.M.L. carried out the experiments; L.R. and M.I. evaluated the data. All authors contributed to the interpretation of the results and commented on the manuscript.

\section{Conflicts of Interest}

The authors declare no conflict of interest.

\section{References}

1. Ding, T.; Schloss, P.D. Dynamics and associations of microbial community types across the human body. Nature 2014, 509, 357-360.

2. O'Malley, M.A. Everything is everywhere: But the environment selects: Ubiquitous distribution and ecological determinism in microbial biogeography. Stud. Hist. Philos. Biol. Biomed. Sci. 2008, 39, 314-325.

3. Schwendicke, F.; Dörfer, C.E.; Schlattmann, P.; Page, L.F.; Thomson, W.M.; Paris, S. Socioeconomic Inequality and Caries: A Systematic Review and Meta-Analysis. J. Dent. Res. 2015, 94, 10-18.

4. Southerland, J.H.; Taylor, G.W.; Moss, K.; Beck, J.D.; Offenbacher, S. Commonality in chronic infammatory diseases: Periodontitis, diabetes and coronary artery disease. Periodontol. 2000 2006, 40, 130-143.

5. Ehrlich, G.D.; Hu, F.Z.; Sotereanos, N.; Sewicke, J.; Parvizi, J.; Nara, P.L.; Arciola, C.R. What role do periodontal pathogens play in osteoarthritis and periprosthetic joint infections of the knee? J. Appl. Biomater. Funct. Mater. 2014, 12, 13-20.

6. Cochis, A.; Azzimonti, B.; Della Valle, C.; Chiesa, R.; Arciola, C.R.; Rimondini, L. Biofilm formation on titanium implants counteracted by grafting gallium and silver ions. J. Biomed. Mater. Res. A 2015, 103, 1176-1187. 
7. Giordano, C.; Saino, E.; Rimondini, L.; Pedeferri, M.P.; Visai, L.; Cigada, A.; Chiesa, R. Electrochemically induced anatase inhibits bacterial colonization on Titanium Grade 2 and Ti6Al4V alloy for dental and orthopedic devices. Colloids Surf. B Biointerfaces 2011, 88, 648-655.

8. Zaura, E.; Nicu, E.A.; Krom, B.P.; Keijser, B.J. Acquiring and maintaining a normal oral microbiome: Current perspective. Front. Cell Infect. Microbiol. 2014, 4, 85, doi:10.3389/fcimb.2014.00085.

9. Varoni, E.; Tarce, M.; Lodi, G.; Carrassi, A. Chlorhexidine (CHX) in dentistry: State of the art. Minerva Stomatol. 2012, 61, 399-419.

10. Brambilla, E.; Ionescu, A.; Gagliani, M.; Cochis, A.; Arciola, C.R.; Rimondini, L. Biofilm formation on composite resins for dental restorations: An in situ study on the effect of chlorhexidine mouthrinses. Int. J. Artif. Organs 2012, 35, 792-799.

11. Eick, S.; Goltz, S.; Nietzsche, S.; Jentsch, H.; Pfister, W. Efficacy of chlorhexidine digluconate-containing formulations and other mouthrinses against periodontopathogenic microorganisms. Quintessence Int. 2011, 42, 687-700.

12. Hidalgo, E.; Dominguez, C. Mechanisms underlying chlorhexidine-induced cytotoxicity. Toxicol. In Vitro 2001, 15, 271-276.

13. Hoffmann, T.; Bruhn, G.; Richter, S.; Netuschil, L.; Brecx, M. Clinical controlled study on plaque and gingivitis reduction under long-term use of low-dose chlorhexidine solutions in a population exhibiting good oral hygiene. Clin. Oral Investig. 2001, 5, 89-95.

14. Cochis, A.; Fracchia, L.; Martinotti, M.G.; Rimondini, L. Biosurfactants prevent in vitro Candida albicans biofilm formation on resins and silicon materials for prosthetic devices. Oral Surg. Oral Med. Oral Pathol. Oral Radiol. 2012, 113, 755-761.

15. Van Staden, A.D.; Dicks, L.M. Calcium orthophosphate-based bone cements (CPCs): Applications, antibiotic release and alternatives to antibiotics. J. Appl. Biomater. Funct. Mater. 2012, 10, 2-11.

16. Hammer, K.A.; Heel, K.A. Use of multiparameter flow cytometry to determine the effects of monoterpenoids and phenylpropanoids on membrane polarity and permeability in staphylococci and enterococci. Int. J. Antimicrob. Agents 2012, 40, 239-245.

17. Khoury, M.; El Beyrouthy, M.; Ouaini, N.; Iriti, M.; Eparvier, V.; Stien, D. Chemical composition and antimicrobial activity of the essential oil of Juniperus excelsa M. Bieb. growing wild in Lebanon. Chem. Biodivers. 2014, 11, 825-830.

18. Fadli, M.; Chevalier, J.; Saad, A.; Mezrioui, N.E.; Hassani, L.; Pages, J.M. Essential oils from Moroccan plants as potential chemosensitisers restoring antibiotic activity in resistant Gram-negative bacteria. Int. J. Antimicrob. Agents 2011, 38, 325-330.

19. Ünlü, M.; Vardar-Unlü, G.; Vural, N.; Donmez, E.; Ozbas, Z.Y. Chemical composition, antibacterial and antifungal activity of the essential oil of Thymbra spicata L. from Turkey. Chem. Nat. Compd. 2009, 23, 572-579.

20. Weli, A.M.; Al-Hinai, S.R.K.; Hossain, M.M.; Al-Sabahi, J.N. Composition of essential oil of Omani Juniperus excelsa fruit and antimicrobial activity against foodborne pathogenic bacteria. J. Taibah Univ. Sci. 2014, 8, 225-230. 
21. Cantrell, C.L.; Zheljazkov, V.D.; Carvalho, C.R.; Astatkie, T.; Jeliazkova, E.A.; Rosa, L.H. Dual Extraction of Essential Oil and Podophyllotoxin from Creeping Juniper (Juniperus horizontalis). PLoS ONE 2014, 9, e106057.

22. Nizar, Y.S.; Muller, C.D.; Lobstein, A. Major bioactivities and mechanism of action of essential oils and their components. Flavour Fragr. J. 2013, 28, 269-279.

23. Takarada, K.; Kimizuka, R.; Takahashi, N.; Honma, K.; Okuda, K.; Kato, T. A comparison of the antibacterial efficacies of essential oils against oral pathogens. Oral Microbiol. Immunol. 2004, 19, 61-64.

24. Pan, P.C.; Harper, S.; Ricci-Nittel, D.; Lux, R.; Shi, W. In-vitro evidence for efficacy of antimicrobial mouthrinses. J. Dent. 2010, 38, 16-20.

25. Quintas, V.; Prada-López, I.; Prados-Frutos, J.C.; Tomás, I. In situ antimicrobial activity on oral biofilm: Essential oils vs. 0.2\% chlorhexidine. Clin. Oral Investig. 2015, 19, 97-91.

26. Tsourounakis, I.; Palaiologou-Gallis, A.A.; Stoute, D.; Maney, P.; Lallier, T.E. Effect of essential oil and chlorhexidine mouthwashes on gingival fibroblast survival and migration. J. Periodontol. 2013, 84, 1211-1220.

27. Zhu, J.; Lower-Nedza, A.D.; Hong, M.; Jie, S.; Wang, Z.; Yingmao, D.; Tschiggerl, C.; Bucar, F.; Brantner, A.H. Chemical composition and antimicrobial activity of three essential oils from Curcuma wenyujin. Nat. Prod. Commun. 2013, 8, 523-526.

28. Helmi, Z.; Al Azzam, K.M.; Tsymbalista, Y.; Ghazleh, R.A.; Shaibah, H.; Aboul-Enein, H. Analysis of Essential Oil in Jerusalem Artichoke (Helianthus tuberosus L.) Leaves and Tubers by Gas Chromatography-Mass Spectrometry. Adv. Pharm. Bull. 2014, 4, 521-526.

29. Adams, R.P. Identification of Essential Oil Components by Gas Chromatography/Mass Spectroscopy. J. Am. Soc. Mass Spectrom. 2005, 16, 1902-1903.

30. Harrison, J.J.; Stremick, C.A.; Turner, R.J.; Allan, N.D.; Olson, M.E.; Ceri, H. Microtiter susceptibility testing of microbes growing on peg lids: A miniaturized biofilm model for high-throughput screening. Nat. Protoc. 2010, 5, 1236-1254.

Sample Availability: Sample of the essential oil is available from the authors.

(C) 2015 by the authors; licensee MDPI, Basel, Switzerland. This article is an open access article distributed under the terms and conditions of the Creative Commons Attribution license (http://creativecommons.org/licenses/by/4.0/). 